\title{
The Character and Economic Preference of City Network of China: A Study Based on the Chinese Global Fortune 500 Enterprises
}

\author{
Xinzheng Zhao, ${ }^{1,2,3}$ Jing Su, ${ }^{1}$ Jing Chao, ${ }^{1}$ Xiaoqiong Liu, ${ }^{1,2,3}$ Tongsheng Li, ${ }^{1,2,3}$ \\ and Yang Rui $\mathbb{D}^{1,2,3}$ \\ ${ }^{1}$ College of Urban and Environmental Science, Northwest University, Xi'an 710127, China \\ ${ }^{2}$ Key Laboratory of Earth Surface System and Environmental Carrying Capacity of Shaanxi Province, Northwest University, \\ Xian 710127, China \\ ${ }^{3}$ Shaanxi Institute of Provincial Resource, Environment and Development, Xi'an 710127, China
}

Correspondence should be addressed to Yang Rui; ruiyang@nwu.edu.cn

Received 15 May 2020; Revised 13 July 2020; Accepted 27 July 2020; Published 28 September 2020

Guest Editor: Jun Yang

Copyright (c) 2020 Xinzheng Zhao et al. This is an open access article distributed under the Creative Commons Attribution License, which permits unrestricted use, distribution, and reproduction in any medium, provided the original work is properly cited.

\begin{abstract}
Based on the data of Chinese enterprises that entered the Fortune 500 list in 2015, this paper utilizes the eclectic model to construct the inter-city association network. Using the network analysis method, the spatial connection characteristics of 311 inter-city networks at prefecture level and above and 20 urban agglomerations networks in China are examined, respectively. The research found the following: (1) the overall connectivity of city network is poor, the centripetal concentration is strong, and the network is not complete. The city network structure shows three tendencies, with a concentration in political centers, a concentration in coastal areas, and a concentration in resource-based cities. The external economic dependence of each node city in national city network is high, and the city network structure has distinctly flattening characteristics. (2) Network function of cities is obviously different in multiscale region. Large cities and regional centers have more balanced function systems than the small- and mediumsized cities do. (3) The network of urban agglomerations is characterized by decentralization of power, differentiation of status, and dependence on external connections. The radiation effect of three major urban agglomerations in coastal China is strong, but the radiation effect of other urban agglomerations needs to be strengthened. (4) Both city networks and agglomeration economies have positive impact on economic growth of the city. The economic performance of city networks is differentiated between urban agglomeration cities and nonurban agglomeration cities, as well as between cities of different scale levels. This study provides new evidence for understanding the spatial relations and expansion of Chinese city networks.
\end{abstract}

\section{Introduction}

Along with the development of globalization and information technology, GaWC research group developed the network paradigm in urban system research area by combining various theories including "Space of flows" [1], "Global City" [2], and "World City" [3-5]. At present, city network research has gradually developed many branches, such as information city network, infrastructure network, and urban economic connection network [6, 7]. Among them, the economic connection network receives much attention because it is the base of linkages among cities.
Generally, urban economic connection network research takes both macro- and microapproaches. On the macroaspect, the gravity model is often adopted to transform the attribute index of cities into economic connection index of intercities. On the microaspect, the organization network among enterprise groups is always examined to measure the connection of intercities. Compared to the gravity model, the perspective of enterprise network approach is more popular for its easiness in reflecting the complexity of the economic connection among cities. City network research based on the perspective of enterprise network is now the hot spot and frontier of urban geography research $[6,8,9]$. 
It is a key step to establish a transform model from enterprise network to city network in city network research based on the perspective of enterprise network. Interlocking network model [10], which was established based on advanced producer service enterprises by GaWC, may be the most influential model at present. The basic assumption of the interlocking network model is that there are linkages between any two branches within the same enterprise groups, which has been examined by scholars such as Rozenblat and Pumain and Alderson et al. [11-13]. Based on some detailed research, Rozenblat and Pumain pointed out that linkages within enterprise groups only existed among some branches [11]. Alderson emphasized the headquarterbranch linkage and put forward the vertical model in the empirical research of the world city network, based on the data of top 500 multinational corporations. Based on the vertical model, the city network research can be extended from advanced produce services to the whole industrial enterprises groups. This progress extends the city network from developed countries to developing countries as most of them are undergoing industrialization. Neal and Liu argued that transformation from enterprise network to city network model is essentially a transformation from a 2-model network of "enterprise-city" to a 1-model network of "city-city" $[14,15]$. To avoid information loss, one option is to analyze the 2-model network of "enterprise-city" directly without transformation. Hennemann and Derudder proposed a regional core city model characterized by hierarchical and geographic features [16]. Considering both regional and hierarchical network features, Zhao et al. put forward some improvement to the regional core city model [17]. Model building had been becoming a hot area of city network research since the AAG special session of "GaWC's Interlocking Network Model-Foundations, Applications and Critiques" in 2012. In short, there is still a lack of a widely accepted model for transforming from enterprise network connections to urban network connections.

The multiple-scale network function of a city (or urban agglomerations) is a new direction of city network research. Labor division has led to a trend that the urban economic associated with a larger area than the traditional hinterland. The links between cities in multiple-scale regions provide them global, national, regional, and local functions. It is worth noting that the functional linkages between multiscale city-regions are not independent. Rozenblat suggested that intracity interactions increase the weight of cities' external connections [18]. Because the multiscale function of the city reflects the competitive advantage of the city in different scale regions, the multiple-scale network function analysis of city will help us to reveal the organizational law of the city network. Furthermore, urban agglomerations have been gradually recognized as the basic unit participating in global competition, and a leading factor for country's sustained and healthy economic development and international competitiveness. The competitiveness of urban agglomerations originates from two perspectives: the internal agglomeration economic effect and the external network connection. Therefore, studies on the complex network connection of urban agglomerations will not only help us to understand the network organization law of urban agglomerations but also help us to understand the effectiveness of urban agglomerations.

Another emerging research direction is the external economic impact of city networks [19]. Externality of city networks proposed by Capello [20] emphasized synergies and complementary effects and effects of functional networks between cities. It improved upon the traditional externalities of aggregation [21], which emphasized the additional benefits of geographical proximity. In recent years, some scholars have done some exploratory research on the contribution of city network development to economic growth and the role of regional equity. But their conclusions are far from consensus. Some scholars believed that the embedding of cities in domestic and international city networks has greater effect on urban economic growth than the endogenous factors such as city size [22]. Other scholars argued that not every city can benefit equally from a high level of network embedding because of intercity competition [23]. Some other scholars contended that the externality of city networks across geographical boundaries may replace the role of local agglomeration economy [22-24]. The economic impacts of city networks are also believed to be varied among different regions and industries [25-27]. Studies on the externality of city network are rather new, whether the development of city network affects the growth of city-region economy, and regional equity is largely unknown and has been becoming a new hot spot for city network researchers.

In this study, we proposed an eclectic model that could further refine the links between corporate headquarters and branches, according to some interviews of transnational corporations in this research. Network analysis and GIS method are employed to explore the connection characteristics of both city networks and urban agglomeration networks at the national scale as well as subnational. The regression method was used to measure the economic performance of the functional links of city networks. The majority existing city network studies focused on global city network characteristics on a fixated scale. This study, thus, sheds light on the multiscale performance and impact of globalization in a transitional and developing economy by focusing on the analysis of city network characteristics at the scale of China and urban agglomerations in China. In addition, this research also contributes to a better understanding of how urban networks affect urban economic growth and regional imbalances.

\section{Illustration}

2.1. Study Area. 311 prefecture-level cities and 20 urban agglomerations in Mainland China were selected to be analysis unit. The division and the definition standard of urban agglomerations set by Fang [28] were used in this research (Figure 1). Because of the lack of data on overseas branches of Chinese Global Fortune 500 enterprises, this study only focused on the characteristics of urban networks at the national and regional scales and their correlations. 


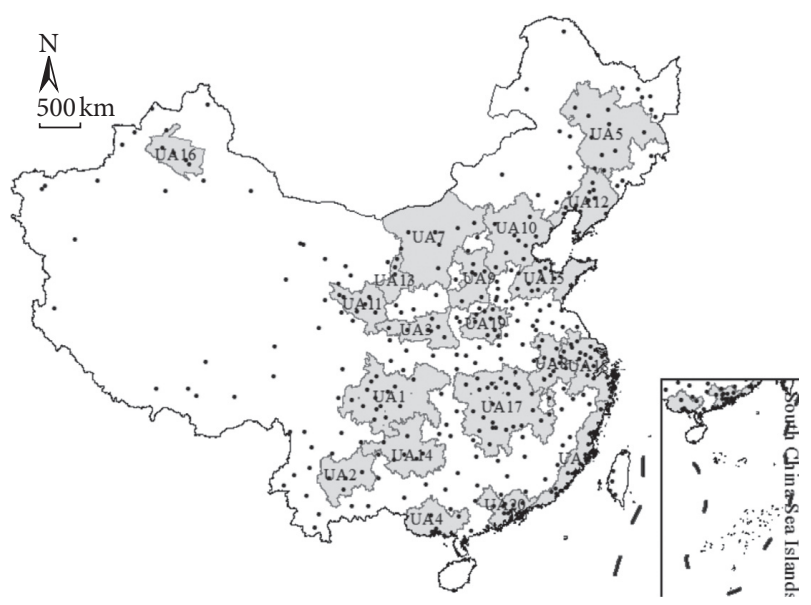

FIgURE 1: Study area. UA1: Chengdu-Chongqing urban agglomeration; UA2: Central Yunnan urban agglomeration; UA3: Guanzhong urban agglomeration; UA4: Guangxi Beibu Gulf urban agglomeration; UA5: Hachang urban agglomeration; UA6: Strait Xi'an urban agglomeration; UA7: Hubao E City Group; UA8: Jianghuai urban agglomeration; UA9: Jinzhong urban agglomeration; UA10: Beijing-Tianjin-Hebei urban agglomeration; UA11: Lanxi urban agglomeration; UA12: Liaoning Central South urban agglomeration; UA13: Ningxia urban agglomeration; UA14: Qianzhong urban agglomeration; UA15: Shandong Peninsula urban agglomeration; UA16: Tianshan North Slope urban agglomeration; UA17: Middle Yangtze urban agglomeration; UA18: Yangtze River Delta urban agglomeration; UA19: Central Plains urban agglomeration; UA20: Pearl River Delta urban agglomeration.

2.2. Data Description. We selected the Chinese enterprises which entered the Fortune 500 list in 2015 as sample and obtained the spatial location information of the enterprise through their official websites. Then, we chose enterprises in two or more prefecture-level cities in Chinese Mainland which have branches to our database. We maintained some Taiwan companies in our database, which had many branches in Mainland China such as Ren Bao PC Limited and Hon Hai Precision Industry. To ensure comparability between the selected branches, we deleted many branches belonging to store level and maintained the enterprise branches with independent legal personality. The final database included 4591 pieces of branch information belonging to 102 enterprises.

2.3. Eclectic Model. Among the branches of enterprise groups, they have formed complicated relationships including both vertical management control and horizontal division of labor and cooperation. The existing city network research literature lacks accurate identification to the linkages among different branches of enterprise groups. The interlocking network model supposed any two branches of the enterprise group had links and exaggerated the horizontal linkages among the internal branches of the enterprise group. The headquarter-branch model emphasized the vertical links (ownership links) among the enterprise group. However, it neglected the horizontal collaboration links among branches of enterprise group. In fact, the enterprise functional department is more and more independent in operation and management, which means the relationship between the functional departments of the enterprise can be used to build connections between subsidiaries within the enterprise group. According to Defever's research [29], branches of multinational corporations can be divided into 6 types: headquarters, R\&D, business department, sales department, productive department, and offices. This research had specified 11 types according to the department function of the subsidiaries and gave them different values according to the importance of department function (Table 1). What is more, we also concluded the law of association among branches within enterprise group, and a weight matrix was set up to judge whether connections among internal branches within enterprise group exist or not. The matrix was based on interview data with 30 managers of the enterprise groups mentioned above. A core content of the interview was to ask the management's views on the main links between the subsidiaries or molecular organizations within the enterprise group. The connection between the two branches would get 1 point for every affirmation of a manager, otherwise 0 points. When the score was above 18 points, it was considered that there was a valid connection between the two branches.

There are four types of connections between the branches within the enterprise (Table 2): (1) Universal topdown connection exists between $X_{1}$ and $X_{2} ; X_{1}$ and $X_{3}$; and $X_{1}$ and $X_{4}$. (2) Conditional top-down connection exists between $X_{4}$ and $X_{5} ; X_{4}$ and $X_{6} ; X_{4}$ and $X_{7} ; X_{4}$ and $X_{10} ; X_{4}$ and $X_{11} ; X_{5}$ and $X_{8}$; and $X_{8}$ and $X_{9}$. (3) Universal horizontal connection exists between $X_{2}$ and $X_{2} ; X_{2}$ and $X_{3} ; X_{2}$ and $X_{4}$; $X_{3}$ and $X_{3} ; X_{3}$ and $X_{4} ; X_{3}$ and $X_{5} ; X_{3}$ and $X_{6} ; X_{3}$ and $X_{7} ; X_{3}$ and $X_{8}$; and $X_{4}$ and $X_{4}$. (4) Conditional horizontal connection exists between $X_{5}$ and $X_{6} ; X_{5}$ and $X_{7} ; X_{6}$ and $X_{6} ; X_{6}$ and $X_{7} ; X_{6}$ and $X_{8} ; X_{6}$ and $X_{11} ; X_{7}$ and $X_{7} ; X_{7}$ and $X_{8} ; X_{8}$ and $X_{8} ; X_{10}$ and $X_{11}$; and $X_{11}$ and $X_{11}$.

Based on the above analysis, the city-city connection matrix is finally constructed by calculating the connectivity value of the enterprise in city. The specific calculation process is as follows:

(1) According to the following formula, the connectivity value between city $i$ and city $j$ is calculated based on company $k$ :

$$
T_{i j, k}=\sum_{m, n} V_{i, k(m)} V_{j, k(n)} W_{\mathrm{mn}, k},
$$

where $T_{i j, k}$ represents the connection strength established by city $i$ and city $j$ based on company $k$ branch. $V_{i, k(m)}$ represents the value of company $k$ 's branch $m$ in city $i . V_{j, k(n)}$ represents the value of company $k$ 's branch $n$ in city j. $W_{\mathrm{mn}, k}$ represents the weight coefficient between branch $X_{m}$ and branch $X_{n}$ of company $k$ (Table 2 ).

(2) We calculate the overall connectivity value between city $i$ and city $j$ according to the following formula: 
TABle 1: Department function of the subsidiaries.

Code: category name (value)

$X_{1}$ : headquarter of the enterprise group (5)

$X_{2}$ : business enterprise serving for headquarters (4)

$X_{3}$ : comprehensive R\&D headquarters (4)

$X_{4}$ : segment business headquarters (4)

$X_{5}$ : market headquarters (4)

$X_{7}$ : segment business enterprise (3)

$X_{8}$ : regional market headquarters (3)

$X_{9}$ : local market sector enterprises (2)

$X_{10}$ : general components manufacturer (2)

$X_{11}$ : special components manufacturer (2)

TABLE 2: Weight matrix.

\begin{tabular}{cccccccccccc}
\hline & $x_{1}$ & $x_{2}$ & $x_{3}$ & $x_{4}$ & $x_{5}$ & $x_{6}$ & $x_{7}$ & $x_{8}$ & $x_{9}$ & $x_{10}$ & $x_{11}$ \\
\hline$x_{1}$ & 0 & 1 & 1 & 1 & 0 & 0 & 0 & 0 & 0 & 0 & 0 \\
$x_{2}$ & 1 & 1 & 1 & 1 & 0 & 0 & 0 & 0 & 0 & 0 & 0 \\
$x_{3}$ & 1 & 1 & 1 & 1 & 1 & 1 & 1 & 1 & 0 & 0 & 1 \\
$x_{4}$ & 1 & 1 & 1 & 1 & $0 / 1$ & $0 / 1$ & $0 / 1$ & 0 & 0 & 1 & $0 / 1$ \\
$x_{5}$ & 0 & 0 & 1 & $0 / 1$ & 0 & $0 / 1$ & $0 / 1$ & $0 / 1$ & 0 & 0 & 0 \\
$x_{6}$ & 0 & 0 & 1 & $0 / 1$ & $0 / 1$ & $0 / 1$ & $0 / 1$ & $0 / 1$ & 0 & 0 & 1 \\
$x_{7}$ & 0 & 0 & 1 & $0 / 1$ & $0 / 1$ & $0 / 1$ & $0 / 1$ & $0 / 1$ & 0 & 0 & 0 \\
$x_{8}$ & 0 & 0 & 1 & 0 & $0 / 1$ & $0 / 1$ & $0 / 1$ & $0 / 1$ & $0 / 0 / 1$ & 0 & 0 \\
$x_{9}$ & 0 & 0 & 0 & 0 & 0 & 0 & 0 & $0 / 0 / 1$ & 0 & 0 & 0 \\
$x_{10}$ & 0 & 0 & 0 & 1 & 0 & 0 & 0 & 0 & 0 & 0 & $0 / 1$ \\
$x_{11}$ & 0 & 0 & 1 & $0 / 1$ & 0 & 1 & 0 & 0 & 0 & $0 / 1$ & $0 / 1$ \\
\hline
\end{tabular}

1 indicates that there is connection between two companies. 0 indicates that there is no connections between two companies. 0/1 indicates that there is connection between two companies if they belong to the same business segments. $0 / 0 / 1$ indicates that there is connection between two companies if they belong not only to the same business segments but also to the same market area.

$$
T_{i j}=\sum_{k} T_{i j, k}
$$

Under the help of computer programs, this study obtained a $311 * 311$ city association matrix. Then we merged cities in the 20 sample urban agglomerations by matrix operation and obtained a $20 * 20$ urban agglomeration association matrix.

\subsection{Measurements Index}

\subsubsection{Network Centrality}

(1) City Network Centrality. In this paper, the degree centrality was used to reflect the status of the cities in the network. And the degree centralization of the graph was used to reflect the tendency of the network structure to the central node. The specific calculation method was as follows:

$$
C_{i}=\sum_{i} T_{i j}, C=\frac{\sum_{i=1}^{n}\left(C_{\max }-C_{i}\right)}{\max \left[\sum_{i}^{n}\left(C_{\max }-C_{i}\right)\right]},
$$

where $C_{i}$ is the absolute degree centrality of the city $i$ in the network. The larger $C_{i}$ is, the higher the degree centrality in the network of the city $i$ is. $C_{\max }$ is the actual maximum centrality in city network. $C$ is the degree centralization of the city network. The bigger $\mathrm{C}$ is, the more the difference in the centrality of each city in the network is. The smaller $\mathrm{C}$ is, the less the difference in the centrality of each city in the network is. When $C=1$, it becomes a star network with only one center. When $C=0$, the centrality of any two cities across the network is the same, and there is no central city.

(2) Urban Agglomeration Network Centrality. Based on the urban agglomeration network matrix, the degree centrality of network and network centralization index are obtained according to the following formula:

$$
M_{t}=\sum_{i=1} C_{t i}, M=\frac{\sum_{i=1}^{n}\left(M_{\max }-M_{i}\right)}{\max \left[\sum_{i=1}^{n}\left(M_{\max }-M_{i}\right)\right]},
$$

where $C_{t i}$ represents the centrality of the city $i$ in the urban agglomeration $t$. $M_{t}$ is the degree centrality of the urban agglomeration $t . M$ is the degree centralization of the total city agglomeration network. $M_{\max }$ is the actual maximum centrality of the urban agglomeration network.

\subsubsection{Regional Network Centrality}

(1) Regional City Network Centrality. Dividing the city network centrality indicators in accordance with their source area, the research gets 4 indicators which reflect the city's function in multiple-scale regions. Self-contained centrality $\left(S_{i}\right)$ reflects the localized agglomeration function and resource of each city. Provincial centrality $\left(P_{i}\right)$, urban agglomeration centrality $\left(A_{i}\right)$, and national centrality $I\left(N_{i}\right)$ reflect the city's network function and resource in province, urban agglomeration (if it belongs to one urban agglomeration), and national scale beyond urban agglomeration:

$$
\begin{aligned}
& S_{i}=T_{i i}, \\
& P_{i}=\sum_{r 1}^{r 2} T_{i j}, A_{i}=\sum_{r 3}^{r 4} T_{i j}, N_{i}=\sum_{r 5}^{r 6} T_{i j},
\end{aligned}
$$

where $T_{i j}$ is the connectivity value between city $i$ and city $j$. $\left\{r_{1}, r_{2}\right\},\left\{r_{3}, r_{4}\right\}$, and $\left\{r_{5}, r_{6}\right\}$, respectively, represent the serial number collection of the provinces, urban agglomeration, and cities outside the urban agglomeration where the city $i$ is located.

(2) Regional Urban Agglomeration Network Centrality. Dividing the urban agglomeration network centrality indicators in accordance with their source area, the research gets 3 indicators which reflect the urban agglomeration function and resource in multiple regions. Urban agglomeration selfcontained centrality $\left(I_{i}\right)$ reflects the agglomeration economy in urban agglomeration scale. Urban agglomeration club centrality $\left(G_{i}\right)$ and urban agglomeration national centrality $\left(E_{i}\right)$ reflect the function and resource of each urban 
agglomeration in and beyond urban agglomeration club. The specific formulas are as follows:

$$
\begin{aligned}
I_{i} & =\sum_{i=k 1, j=k 1}^{i=k 2, j=k 2} T_{i j}, \\
G_{i} & =\sum_{i=k 1, j=k 4}^{i=k 1, j=k 3} T_{i j}, \\
E_{i} & =\sum_{i=k 1, j=k 5}^{i=k 2, j=k 6} T_{i j},
\end{aligned}
$$

where $T_{i j}$ is the connection value between city $i$ and city $j$. $\left\{k_{1}, k_{2}\right\},\left\{k_{3}, k_{4}\right\}$, and $\left\{k_{5}, k_{6}\right\}$, respectively, represent the serial number collections of the cities within urban agglomeration $i$, the cities outside urban agglomeration $i$, and nonurban agglomeration.

2.5. Regression Model. To test the effects of network on urban and regional economic productivity, the research used the prevailing Cobb-Douglas production function that has been widely adopted in the empirical literature on economic growth [30]. Following other studies of urban economic performance [30-32], the research used economic output as the dependent variable. For independent variables, capital and labor are the classic variables inherent in the model. Technological innovation, human capital, foreign capital, industrial foundation, infrastructure, and urban living environment had also been successively proved to have important effects on economic growth in subsequent studies [33]. In this study, both the socioeconomic indicators above and network indicators were included in the regression model to test whether the network indicators had unique contributions in addition to the socio-economic indicators.

The mathematical expression of the Cobb-Douglas function is as follows:

$$
Y=A L^{\alpha} K^{\beta} H^{\gamma} I^{\delta} T^{\varepsilon} P^{\theta} C^{9} N^{\mu} S^{\pi} Q^{\rho} .
$$

A new model can be obtained by logarithmic transformation:

$$
\begin{aligned}
\ln Y= & \ln A+\alpha \ln L+\beta \ln K+\gamma \ln H+\delta \ln I+\varepsilon \ln T \\
& +\theta \ln P+\vartheta \ln C+\mu \ln N+\pi \ln S+\rho \ln Q+\sigma,
\end{aligned}
$$

where $Y$ represents the economic output variable. GDP is used to reflect the economic output variable. $L$ represents the labor variable. The sum of unit practitioners and urban individual and private employees is used to reflect the labor variable. $K$ represents the capital variable. Total investment in fixed assets is used to reflect the capital variable. $H$ represents the human capital variable. The percentage of people with high school education and above is used to reflect the human capital variable. I represents the institute variable. The proportion of government budget expenditure in GDP is used to reflect the institute variable. $T$ represents the facility variable. Per capita road area is used to reflect the facility variable. $P$ represents the foreign direct investment variable. The proportion of FDI in GDP is used to reflect the foreign direct investment variable. $C$ represents the urban life quality variable. The number of hospital beds per 10,000 people is used to reflect the urban life quality variable. $N$ represents the technological innovation variable. The number of patents granted per million people is used to reflect the technological innovation variable. $S$ represents the industrial structure variable. The ratio of output value of manufacturing and service industries is used to reflect the industrial structure variable. $Q$ represents the city network variable. Multiple network indexes including self-centrality, province centrality, national centrality I (connections with cities outside the province), national centrality II, and urban agglomeration centrality are used as the city network variables.

\section{Connection Characteristics of City Network}

3.1. Centrality of City Network Analysis. There are 311 cities in the national city network, accounting for $92 \%$ of the national administrative units, and such a large network scale reflects that Chinese prefecture-level cities have a high degree of participation in China's economic system. According to the single-value network (intercity link values were recorded as 1 ), network density is 0.22 , which indicates that the direct connectivity between the different nodes in the network is low and the stability of the network is weak. According to the single-valued network, the network centralization reaches up to 0.78 , reflecting that China's city network is characterized by centrality; that is, the whole city network connection mainly refers to a few central cities. Thus, China's city network is immature, with poor overall connectivity and stronger centrality.

The distribution of central cities is obviously characterized by political center-based, resource-based coastal agglomeration. Beijing obtains the highest centrality which is 45 times of the average centrality of all cities in the network. Primacy city index (1.38), 4 city index (1.08), and 11 city index (0.93) indicate that Beijing is not only the political capital but also is the first city of China's economic development. In addition, the top 40 cities (Table 3 ) contain 4 municipalities and 26 provincial capital cities. Further analyses reveal that the top 60 cities in centrality include the 13 coastal cities and 9 resource-based cities, meaning that China's city network also is characterized by coastal and resource agglomeration.

3.2. Regional City Network Centrality Analysis. According to the results of the rank-size rule (Table 4 ), the overall centrality index $\left(C_{i}\right)$, the national centrality II $\left(N_{i}\right)$, and the provincial centrality degree $\left(P_{i}\right)$ have a high degree of fit. $Q$ value is close to 1 . It means the distribution characteristics are close to the ideal state. The fit degree of the self-contained centrality is slightly lower than others, and the absolute value of $q$ is much larger than 1 , which is regarded as the centralized scale distribution characteristic. The above results reveal that the city network system evolution follows the rank-size law. However, the large cities have more 
TABLE 3: Top 60 cities of overall centrality.

\begin{tabular}{|c|c|c|c|c|c|c|c|c|c|}
\hline Order $1-12$ & Centrality & Order (13-24) & Centrality & Order $(25-36)$ & Centrality & Order $(37-48)$ & Centrality & Order (49-60) & Centrality \\
\hline Beijing & 329475 & Taiyuan & 34547 & Hohhot & 20562 & Jincheng & 8666 & Baoding & 4395 \\
\hline Shanghai & 137782 & Shijiazhuang & 33371 & Hefei & 20524 & Xiamen & 7244 & Lianyungang & 4181 \\
\hline Shenzhen & 56482 & Chongqing & 30034 & Nanchang & 19094 & Yichang & 7184 & Erdos & 4137 \\
\hline Tianjin & 55617 & Zhengzhou & 29597 & Haikou & 18691 & Cangzhou & 6096 & Yulin & 3887 \\
\hline Xi'an & 48777 & Changchun & 28344 & Harbin & 17951 & Zhuhai & 5600 & Yantai & 3863 \\
\hline Wuhan & 48522 & Jinan & 28028 & Xining & 15566 & Changzhou & 5436 & Quanzhou & 3848 \\
\hline Nanjing & 48442 & Changsha & 27429 & Yinchuan & 15370 & Rizhao & 5396 & Yangzhou & 3705 \\
\hline Hong Kong & 46807 & Fuzhou & 25741 & Tangshan & 13728 & Anshan & 5391 & Xingtai & 3649 \\
\hline Chengdu & 44546 & Kunming & 25402 & Qindao & 13200 & Luoyang & 5247 & Panjin & 3647 \\
\hline Guangzhou & 43193 & Urumqi & 23394 & Dalian & 11675 & Langfang & 4692 & Foshan & 3621 \\
\hline Hangzhou & 42714 & Lanzhou & 21040 & Ningbo & 10148 & Handan & 4581 & Zibo & 3614 \\
\hline Shenyang & 36839 & Guiyang & 20822 & Suzhou & 9502 & Jiuquan & 4478 & Daqing & 3556 \\
\hline
\end{tabular}

advantages in realizing urban self-economic supporting functions than small- and medium-sized cities.

Based on the urban centrality degree, the provincial centrality degree, and the national centrality degree, 72 cities were selected and classified into three categories (Table 5) according to the criteria of "mean +1 standard deviation". Type I was named as balanced and comprehensive development type. These cities are outstanding in both local agglomeration economy and external network connections and resources.

Including 21 cities, 17 of them have obvious advantages in the self-contained function, provincial functions, and national functions. The last four cities are Chengdu, Datong, Changzhi, and Anshan. Chengdu is weak in the provincial function, while the remaining three cities are weak in the national function. Type II was named as notbalanced and comprehensive development type. They have advantages in national function and provincial function, but they are weak in local agglomeration economy. There are 18 cities included in that type. Type III was named as single function development type, specifically including the local function oriented in III-1 and the national function oriented in III-2. Type III-1 refers to 29 cities which have advantages in provincial function. Type III-2 refers to 4 cities including Xining, Yinchuan, Xiamen, and Cangzhou, which only have advantages in national function.

\section{Connection Characteristics of Urban Agglomeration Network}

4.1. Centrality of Urban Agglomeration Network. There are total 20 urban agglomerations in our research (Table 6). The first urban agglomeration in centrality is BeijingTianjin-Hebei urban agglomeration, which is 5 times of the average centrality of whole urban agglomeration network. Top 5 urban agglomerations in centrality are national urban agglomerations. Top 5 urban agglomeration's centrality is 5 times that of the 9 regional urban agglomerations and 7 times that of 6 local urban agglomerations. It indicates that there is a large difference between the different levels of network centrality. Within the 9 regional urban agglomerations, the centrality in urban agglomerations in middle-south Liaoning province is more than twice that of Jianghuai urban agglomeration. It indicates obviously uneven development between urban agglomerations at the same level.

\subsection{Regional Urban Agglomeration Network Centrality} Analysis. $Q$ values in rank-size analysis based on overall centrality $\left(M_{t}\right)$, the club centrality $\left(\left(G_{i}\right)\right)$, and the national centrality $\left(E_{i}\right)$ of the urban agglomeration are close to 1 . It indicates that the external function of urban agglomeration followed the rank-size distribution. But the $q$ value in ranksize analysis based on self-contained centrality of urban agglomeration $\left(I_{i}\right)$ is close to 2 . It shows a significant clustering distribution characteristic.

According to the criteria of "mean +1 standard deviation," a screening analysis is carried out, based on the urban agglomeration self-contained degree, the urban agglomeration club centrality degree, and the national centrality II degree. We found that Yangtze River Delta and Beijing, Tianjin, and Hebei urban agglomerations have prominent advantages in both agglomeration economy in urban agglomeration and external network connection to other cities within urban agglomerations club and even to other cities outside the urban agglomeration club. The Pearl River Delta urban agglomeration has obvious advantages in external network connection to the cities of urban agglomeration club, but the agglomeration economy within Pearl River Delta urban agglomeration is not outstanding. Other urban agglomerations do not show any prominent advantage in agglomeration economy in urban agglomeration and external network connection to other cities. It is obvious that the development level of three major urban agglomerations is higher than that of other urban agglomerations. Achieving breakthroughs in specific regional functions will become an important task for the development of urban agglomerations. Therefore, it will be an important task for most urban agglomerations to make a breakthrough in specific regional functions. 


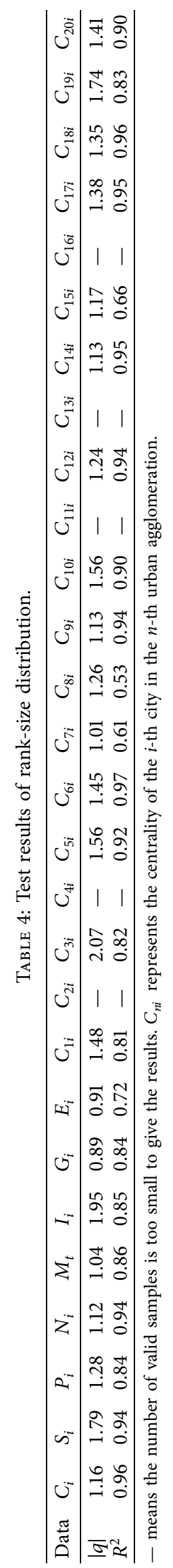


TABLE 5: Classification of city's network function.

\begin{tabular}{|c|c|c|c|c|c|}
\hline \multirow{2}{*}{$\frac{\text { Type I }}{\text { Beijing }}$} & \multicolumn{5}{|c|}{ Type II } \\
\hline & Hong Kong & Taiyuan & Hohhot & Jinan & Changsha \\
\hline Shanghai & Nanjing & Shijiazhuang & Lanzhou & Shenyang & Haikou \\
\hline Tianjin & Shenzhen & Tangshan & Fuzhou & Hefei & Nanchang \\
\hline Xi'an & Suzhou & Zhengzhou & Urumqi & Ningbo & Yichang \\
\hline Wuhan & Hangzhou & Changchun & Chongqing & Qingdao & Guiyang \\
\hline Guangzhou & Jincheng & Chengdu* & Harbin & Dalian & Kunming \\
\hline Datong** & Changzhi** & Anshan** & & & \\
\hline \multicolumn{6}{|l|}{ Type III } \\
\hline III-1 & Yancheng & Changzhou & Luoyang & Jilin & Handan \\
\hline Xianyang & Yangzhou & Shiyan & Xiangyang & Xingtai & Foshan \\
\hline Zhuhai & Yan'an & Jinzhong & Zhenjiang & Huaian & Rizhao \\
\hline Zhangjiakou & Binzhou & Shuozhou & Huizhou & Shangrao & Weinan \\
\hline Yingtan & Langfang & Zhongshan & Nantong & Erdos & Yulin \\
\hline III-2 & Xining & Yinchuan & Xiamen & Cangzhou & \\
\hline
\end{tabular}

TABLE 6: Overall centrality of urban agglomeration.

\begin{tabular}{lc}
\hline UA (code) & Centrality (order) \\
\hline UA10 & $455386(1)$ \\
UA18 & $274965(2)$ \\
UA20 & $133552(3)$ \\
UA17 & $125649(4)$ \\
UA1 & $84110(5)$ \\
UA12 & $70570(6)$ \\
UA15 & $69325(7)$ \\
UA5 & $62181(8)$ \\
UA3 & $57291(9)$ \\
UA6 & $47146(10)$ \\
UA9 & $41778(11)$ \\
UA19 & $40408(12)$ \\
UA11 & $38008(13)$ \\
UA7 & $37140(14)$ \\
UA8 & $33331(15)$ \\
UA2 & $27466(16)$ \\
UA16 & $26880(17)$ \\
UA14 & $24725(18)$ \\
UA13 & $18238(19)$ \\
UA4 & $4787(20)$ \\
\hline
\end{tabular}

\section{Economic Performance of City Network}

All the 311 cities were included in models 1-4 (Table 7) to examine the economic effect of city network in national scale. There were only economic indicator variables in model 1. City network variables such as provincial centrality, national centrality II, and self-contained centrality was taken into the regression models 2,3 , and 4 , respectively. 74 cities of five major urban agglomerations were included in models 5-8 (Table 7) to examine the economic effect of city network within urban agglomeration. There were only economic indicator variables in model 5. City network variables such as self-contained centrality, urban agglomeration centrality, and national centrality I were taken into the regression models 6,7 , and 8, respectively. 10 megacities and 48 small cities were included in models 9-11 and 12-14 (Table 7), respectively, to examine the economic effect difference of city network between different city sizes. There were only economic indicator variables in model 9 and model 12. City network variables such as self-contained centrality and national centrality II were taken into the regression models 10 and 11, respectively. Provincial centrality and national centrality II were taken into the regression models 13 and 14, respectively. Stepwise regression was used in all regression progress.

In national scale (models 1-4), both city network connection and agglomeration economy within city scale are proved positively to contribute to economic growth of the city, according to the significant positive regression coefficient of provincial centrality, national centrality II, and self-contained centrality in models 2-3. The contribution of city network links within province to economic growth of the city is higher than that of city network links outside the province can also be found, by comparing the regression coefficient.

In urban agglomeration scale (models 5-8), both city network connection and agglomeration economy within city scale are also proved positively to contribute to economic growth of the city. In addition, positive contribution of urban agglomeration economy to economic growth of the city is also conformed. The external network connections beyond urban agglomeration contribute more to the economic growth of the city than that of the network connection within the urban agglomeration.

For the cities in different sizes (models 9-14), there are some different findings. City network variable is only significant and positive in 10 megacities and 48 small cities. It indicates the uneven economic benefit of the embedding to city network. Further analysis shows that small cities' economic growth is only driven by external connections, especially the connections to the cities outside the province. However, megacities' economic growth is driven by both external connections and agglomeration economy.

The regression result of the most attribute variables is in line with existing studies. Positive contribution of capital, facility, urban quality of life, and technological innovation to economic performance of the city, as well as negative contribution of 


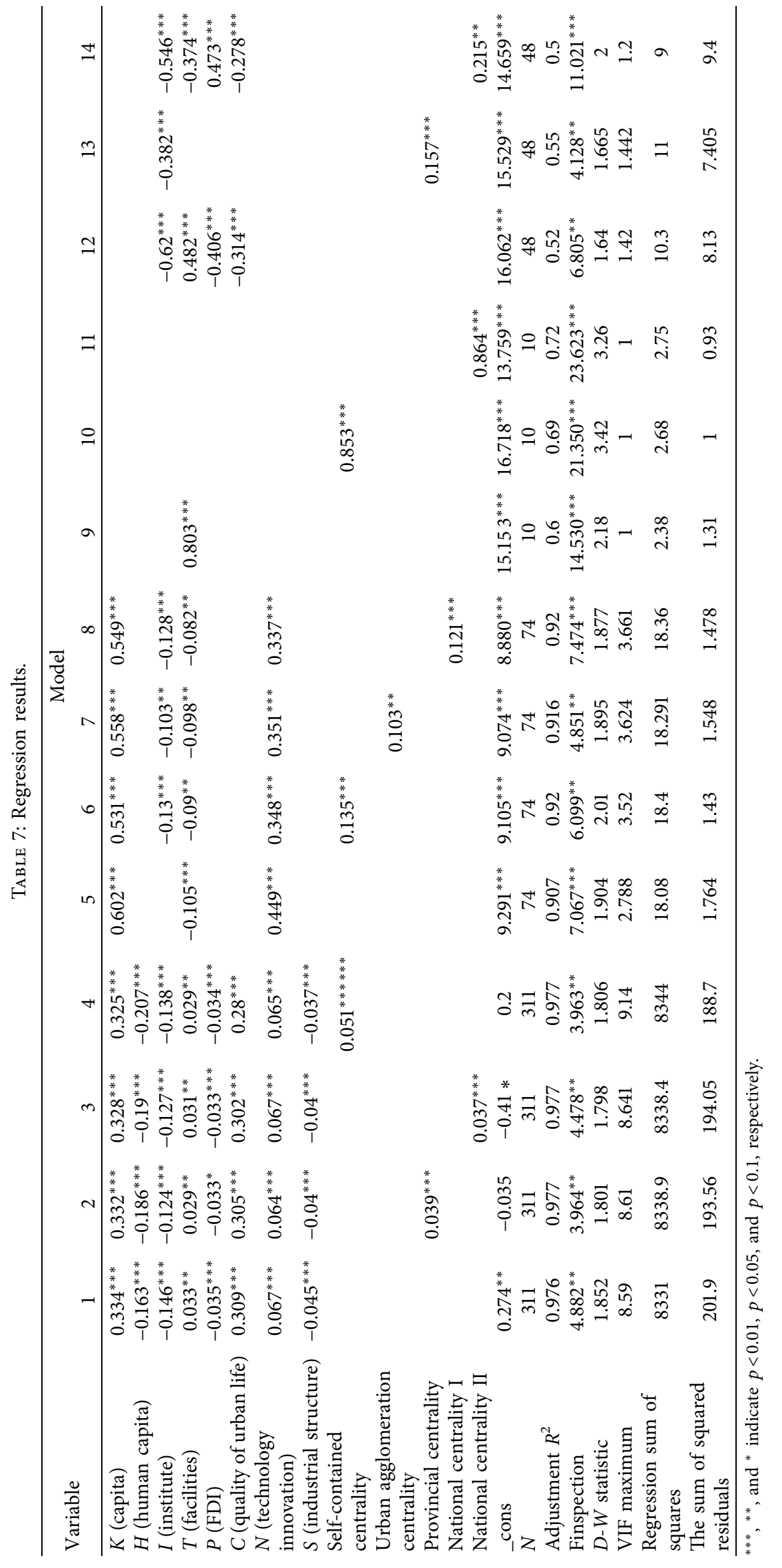


government role and industry structure, is confirmed in some regression models. Some of the attribute variables were excluded when the city network variable was put into the model, which indicates a certain substitution relationship between economic factors and external network connections.

\section{Conclusions and Discussion}

6.1. Conclusions. Based on the data of Chinese enterprises that entered the Fortune 500 list in 2015, this paper proposes an eclectic model to capture the intercity association network. Using the network analysis method, the spatial connection characteristics of 311 intercity networks at prefecture level and above and 20 urban agglomerations networks in China are examined.

The overall connectivity of city network is poor, the centripetal concentration is strong, and the network is not complete. The city network structure shows three tendencies, with a concentration in political centers, a concentration in coastal areas, and a concentration in resourcebased cities. The external economic dependence of each node city in national city network is high, and the city network structure has distinctly flattening characteristics. Network function of cities is obviously different in multiscale region. Large cities and regional centers have more balanced function systems than the small- and mediumsized cities do.

The network of urban agglomerations is characterized by decentralization of power, differentiation of status, and dependence on external connections. The radiation effect of three major urban agglomerations in coastal China is strong, but radiation effect of other urban agglomerations needs to be strengthened.

Both city networks and agglomeration economies have positive impact on the economic growth of the city. The economic performance of city networks is differentiated between urban agglomeration cities and nonurban agglomeration cities, as well as between cities of different scale levels. The economic growth of megacities depends on both agglomeration economy and network resources, while small cities can only rely passively on the resources obtained from external contacts.

6.2. Discussion. Big data composed of many enterprise groups is a popular choice for the simulation of city networks. However, the complexities and intricacies of the relationship between the branches among enterprise group make such a simulation fraught with uncertainty. In response to this problem, this study adopts a semistructured questionnaire interview method to obtain accurate contact data between branches among enterprise groups and proposes a new eclectic model to improve the accuracy of simulating city network connections, based on enterprise group big data. This method of improving the accuracy of big data simulation based on small data models obtained from questionnaire interviews is very effective in complex network research.

Although the eclectic network model was used to better simulate the urban network connection from the perspective of the enterprise network, the city network was still chartered by low density, centripetal distribution, and network node polarization. This is consistent with the results from other research [34]. To be noted, the database of Chinese Global Fortune 500 enterprises used in this article is rather a new database. What is more, most of the enterprises in the database are state-owned companies; therefore the research of this article presents strong "political characteristics." Thus, the findings for this research is expected to be different from the studies drew upon the low status of the political center city in the city network [35]. In addition, the impact of the city's network status on the city's economic performance implies that urban economic policy should not solely focus on the promotion of traditional economic factors such as capital, technology, and labor; instead, they should also actively promote the city's network status to improve economic growth. This is particularly important for small cities with strong external connection dependence.

The paper also has certain limitations which provide possible future research opportunities: first, because the time information of establishment of the enterprise is not completely obtained, this article only studied the characteristics of the city (group) network connection in 2015. There is a lack of dynamic evolution analysis about the city network characteristics. Second, because of the lack of detailed global investment data of the Chinese Global Fortune 500 enterprises, this study only focused on the character and correlation at national and regional scales. The global scale was not included in this study.

\section{Data Availability}

Chinese enterprises which entered the Fortune 500 list in 2015 were the core data of this article. We get the spatial location information of the enterprise headquarters and branches through the inquiry of the official website of the enterprise. The data are available from Xinzheng Zhao upon request via e-mail (xzzhao@nwu.edu.cn).

\section{Conflicts of Interest}

The authors declare that they have no conflicts of interest.

\section{Acknowledgments}

This research was supported by the National Natural Science Foundation of China (No. 41401184), MOE (Ministry of Education in China) Project of Humanities and Social Sciences (No. 14YJCZH222), Soft Science Research Program of Shaanxi Province, China (No. 2019KRM071), and Shaanxi Key Laboratory of Earth Surface System and Environmental Carrying Capacity at Northwest University (No. SKLESS201806).

\section{References}

[1] M. Castells, The Rise of Network Society, Blackwell, Oxford, UK, 1996. 
[2] S. Sassen, The Global City, Princeton University Press, Princeton, NJ, USA, 1991.

[3] P. Hall, The World Cities, Weidenfeld and Nicolson, London, UK, 1966.

[4] J. Friedmann and G. Wolff, "World city formation: an agenda for research and action," International Journal of Urban and Regional Research, vol. 6, no. 3, pp. 309-344, 1982.

[5] J. Friedmann, "The world city hypothesis," Development and Change, vol. 17, no. 1, pp. 69-83, 1986.

[6] B. Derudder, "On conceptual confusion in empirical analyses of a transnational urban network," Urban Studies, vol. 43, no. 11, pp. 2027-2046, 2006.

[7] J. Lu, D. Sun, J. Yu, J. Li, and F. Niu, “"Local versus nonlocal” enterprise linkages of global cities: a comparison between Beijing and Shanghai, China," Complexity, vol. 2020, Article ID 8918534, 13 pages, 2020.

[8] X. Zhao, Q. Li, Y. Rui, X. Liu, and T. Li, “The characteristics of urban network of China: a study based on the Chinese companies in the fortune global 500 list," Acta Geographica Sinica, vol. 74, no. 4, pp. 80-95, 2019.

[9] X. Liu and B. Derudder, "Analyzing urban networks through the lens of corporate networks: a critical review," Cities, vol. 31, no. 2, pp. 430-437, 2013.

[10] P. Taylor, "Specification of the world city network," Geographical Analysis, vol. 33, no. 2, pp. 181-194, 2001.

[11] C. Rozenblat and D. Pumain, "Firm linkages, innovation and evolution of urban systems," in Cities in Globalization Routledge, London, UK, 2007.

[12] A. S. Alderson and J. Beckfield, "Power and position in the world city system," American Journal of Sociology, vol. 109, no. 4, pp. 811-851, 2004.

[13] A. S. Alderson, J. Beckfiled, and S. J. Jessica, "Intercity relations and globalization: the evolution of the global urban hierarchy, 1981-2007," Urban Studies, vol. 47, no. 9, pp. 1899-1923, 2010.

[14] Z. Neal, "The duality of world cities and firms: comparing networks, hierarchies, and inequalities in the global economy," Global Networks, vol. 8, no. 1, pp. 94-115, 2008.

[15] X. Liu and B. Derudder, "Two-mode networks and the interlocking world city network model: a reply to neal," Geographical Analysis, vol. 44, no. 2, pp. 171-173, 2012.

[16] S. Hennemann and B. Derudder, "An alternative approach to the calculation and analysis of connectivity in the world city network," Environment and Planning B: Planning and Design, vol. 41, no. 3, pp. 392-412, 2014.

[17] M. Zhao, K. Wu, X. Liu, and D. Ben, "A novel method for approximating intercity networks: an empirical comparison for validating the city networks in two Chinese city-regions," Journal of Geographical Sciences, vol. 25, no. 3, pp. 337-354, 2015.

[18] C. Rozenblat, "Opening the black box of agglomeration economies for measuring cities' competitiveness through international firm networks," Urban Studies, vol. 47, no. 13, pp. 2841-2865, 2010.

[19] B. Lin, R Gu, J. Wang, and X. Bi, "From agglomeration externalities to network externalities of crossing borders: frontier progress of agglomeration economics," Urban Development Studies, vol. 25, no. 12, pp. 82-89, 2018.

[20] R. Capello, "The city network paradigm: measuring city network externalities," Urban Studies, vol. 37, no. 11, pp. 1925-1945, 2000.

[21] R. Rosenthal and W. C. Strange, Handbook of Regional \& Urban Economics, North Holland, Amsterdam, Netherlands, 2004.
[22] P. McCann and Z. J. Acs, "Globalization: countries, cities and multinationals," Regional Studies, vol. 45, no. 1, pp. 17-32, 2011.

[23] M. van Meeteren, Z. Neal, and B. Derudder, "Disentangling agglomeration and network externalities: a conceptual typology," Papers in Regional Science, vol. 95, no. 1, pp. 55-62, 2016.

[24] M. Fujita and N. Hamaguchi, "Supply chain internationalization in East Asia: inclusiveness and risks," Papers in Regional Science, vol. 95, no. 1, pp. 81-100, 2016.

[25] E. J. Meijers and S. Borrowed, "Agglomeration shadows and cultural amenities in north-west Europe," European Planning Studies, vol. 23, no. 6, pp. 1090-1109, 2015.

[26] E. L. Glaeser, G. A. M. Ponzetto, and Y. Zou, "Urban networks: connecting markets, people, and ideas," Papers in Regional Science, vol. 95, no. 1, pp. 17-59, 2016.

[27] R. Camagni, R. Capello, and A. Caragliu, "Static vs. dynamic agglomeration economies. Spatial context and structural evolution behind urban growth," Papers in Regional Science, vol. 95, no. 1, pp. 133-158, 2016.

[28] C. Fang, "Important progress and future direction of studies on China's urban agglomerations," Journal of Geographical Sciences, vol. 25, no. 8, pp. 1003-1024, 2015.

[29] F. Defever, "Functional fragmentation and the location of multinational firms in the enlarged Europe," Regional Science and Urban Economics, vol. 36, no. 5, pp. 658-677, 2006.

[30] E. J. Meijers and M. J. Burger, "Spatial structure and productivity in US metropolitan areas," Environment and Planning, vol. 42, pp. 1383-1402, 2010.

[31] M. Brülhart and N. A. Mathys, "Sectoral agglomeration economies in a panel of European regions," Regional Science and Urban Economics, vol. 38, no. 4, pp. 348-362, 2008.

[32] A. Ciccone, "Agglomeration effects in Europe," European Economic Review, vol. 46, no. 2, pp. 213-227, 2002.

[33] B. Sun, X. Wang, and Y. Cai, "An empirical study on the economic performance of polycentric spatial structure of mega-cities in China," City Planning Review, vol. 39, no. 8, pp. $39-45,2015$.

[34] K. Wu Kang, C. Fang, and M. Zhao, "The spatial organization and structure complexity of Chinese intercity networks," Geographical Research, vol. 34, no. 4, pp. 711-728, 2015.

[35] X. Zhao and Y. Ning, The Research of Chinese City Network in the Context of Economic Globalization: The Case of Yangtze River, The Commercial Press, Beijing, China, 2012. 